Supporting Information

\title{
A Tellurium-Substituted Heteropolyniobate with Unique $\pi-\pi$ Stacking and Ionic Conduction Property
}

Ping-Xin Wu, $\uparrow$ Rong-Da Lai, $\dagger$ Rui Ge, $\uparrow$ Cai Sun, $\uparrow$ Guo-Qiang Wang, $\dagger$ Xin-Xiong Li, ${ }^{*} \dagger ¥$ Shou-Tian Zheng*†

$\uparrow$ State Key Laboratory of Photocatalysis on Energy and Environment, College of Chemistry, Fuzhou University, Fuzhou, Fujian 350108, China.

$\$$ College of Materials Science and Engineering, Fuzhou University, Fuzhou, Fujian, 350108, China

$¥$ State Key Laboratory of Structural Chemistry, Fujian Institute of Research on the Structure of Matter, Chinese Academy of Sciences, Fuzhou, Fujian 350002, China.

\section{This file includes:}

Section S1 Synthesis and Methods

Section S2 Additional Table

S4-S6

Section S3 Additional Figures

S7 S14

Section 4: References

S15 


\section{Section S1 Synthesis and Methods}

\section{Preparations of $\mathrm{K}_{2} \mathrm{H}\left[\mathrm{Cu}(\text { phen })\left(\mathrm{H}_{2} \mathrm{O}\right)\right]_{4}[\mathrm{Cu}(\text { phen })]_{2}\left[\left(\mathrm{LiNb}_{8} \mathrm{Te}_{4} \mathrm{O}_{40}\right)\right] \cdot 34 \mathrm{H}_{2} \mathrm{O}(1)$}

A mixture of $\mathrm{K}_{7} \mathrm{HNb}_{6} \mathrm{O}_{19} \cdot 13 \mathrm{H}_{2} \mathrm{O}(0.305 \mathrm{~g}, 0.22 \mathrm{mmol}), \mathrm{CuCl}_{2} \cdot 2 \mathrm{H}_{2} \mathrm{O}(0.120 \mathrm{~g}, 2.00 \mathrm{mmol})$, $\mathrm{Na}_{2} \mathrm{CO}_{3}(0.105 \mathrm{~g}, 1.00 \mathrm{mmol}), \mathrm{Li}_{2} \mathrm{~B}_{4} \mathrm{O}_{7}(0.053 \mathrm{~g}, 0.31 \mathrm{mmol}), \mathrm{NaCl}(0.104 \mathrm{~g}, 1.78 \mathrm{mmol}), \mathrm{TeO}_{2}$ (0.109 g, $0.68 \mathrm{mmol}), 1,10$-phenanthroline $(0.02 \mathrm{~g}, 0.11 \mathrm{mmol})$ and $50 \mu \mathrm{L}$ en was added into 8 $\mathrm{mL}$ deionized water. After being stirred for 1 hour, the resulting mixture was sealed in a Teflonlined autoclave $(23 \mathrm{~mL})$ and heated at $120^{\circ} \mathrm{C}$ for 3 days. After the resulting mixture slowly cooled down to room temperature, atrovirens block crystals were obtained. Yield: about $30 \mathrm{mg}$ (10\% based on $\mathrm{Nb}$ ). Anal. Calcd for $\mathrm{C}_{72} \mathrm{H}_{48} \mathrm{Cu}_{6} \mathrm{~K}_{2} \mathrm{LiN}_{12} \mathrm{Nb}_{8} \mathrm{O}_{44} \mathrm{Te}_{4}$ : C, 24.67; H, 1.38; N, 4.80. Found: C, 24.57; H, 1.53; N, 4.61. IR (KBr): 1629, 1610, 1584, 1518, 1494, 1428, 1345, 1315 , 1225, 1147, 1109, 1054, 1035, 860, 770, 721, $544 \mathrm{~cm}^{-1}$. IR (KBr, cm $\left.{ }^{-1}\right): 3220(\mathrm{~m}), 1638(\mathrm{~s})$, 1519(s), 1427(s), 1345(s), 1145(m), 1101(m), 1042(s), 846(s), 760(w), 662(s), 530(w), 473(s) (Fig. S14).

\section{Synthetic Discussion}

During the synthetic process, some factors can affect the crystal growth of 1. Firstly, the amount of $\mathrm{TeO}_{2}$ influences the crystal quality. Although $\mathbf{1}$ could be obtained when increasing or decreasing the amount of $\mathrm{TeO}_{2}$, the crystals with the best quality could only be obtained when the amount of $\mathrm{TeO}_{2}$ is $0.1 \mathrm{~g}$. Secondly, $\mathrm{TeO}_{2}$ was irreplaceable. If $\mathrm{TeO}_{2}$ was replaced by $\mathrm{TeO}_{3}$, no crystal could be obtained. Thirdly, $\mathrm{NaCl}$ can facilitate the crystallization of 1. When it was replaced by $\mathrm{KCl}, \mathrm{LiCl}$, or $\mathrm{CsCl}$, the yield of $\mathbf{1}$ decreased. Finally, if the starting divalent $\mathrm{Cu}^{2+}$ salt was replaced by the other transition metal salts including $\mathrm{CoCl}_{2} \cdot 6 \mathrm{H}_{2} \mathrm{O}$, $\mathrm{NiCl}_{2} \cdot 6 \mathrm{H}_{2} \mathrm{O}, \mathrm{MnCl}_{2} \cdot 4 \mathrm{H}_{2} \mathrm{O}, \mathrm{FeCl}_{2} \cdot 4 \mathrm{H}_{2} \mathrm{O}$, no crystal can be isolated even isostructural compounds.

\section{Materials and General methods}

$\mathrm{K}_{7} \mathrm{H}\left[\mathrm{Nb}_{6} \mathrm{O}_{19}\right] \cdot 13 \mathrm{H}_{2} \mathrm{O}$ precursor was synthesized on the basis of literature method and proved by IR spectroscopy. ${ }^{\mathrm{S} 1}$ Other reactants and solvents were purchased from commercial sources and used for reactions without further purification. PXRD patterns were obtained by using an Ultima IV diffractometer with $\mathrm{Cu}-\mathrm{K} \alpha$ radiation $(\lambda=1.5418 \AA)$ in the range of 5-45․ $\mathrm{UV}$-vis adsorption spectra were collected by using a PerkinElmer Lambda 35 spectrophotometer to monitor the release process. IR spectra were recorded on an Opus Vertex 70 FT-IR infrared spectrophotometer in the range of $400-4000 \mathrm{~cm}^{-1}$. Thermogravimetric analysis was conducted on 
a Mettler Toledo TGA/SDTA 851e analyzer in an argon-flow atmosphere with a heating rate of $10^{\circ} \mathrm{C} / \mathrm{min}$ at $30-800^{\circ} \mathrm{C}$.

\section{Single-crystal structure analysis}

Single crystal X-ray diffraction data for 1 was collected on a Bruker APEX II diffractometer at $175 \mathrm{~K}$ equipped with a fine focus, with $2.0 \mathrm{~kW}$ sealed tube X-ray source (MoK radiation, $\lambda=$

$0.71073 \AA$ Á) operating at $50 \mathrm{kV}$ and $30 \mathrm{~mA}$. The SADABS program was used for absorption correction. The structure was solved by the direct method and refined on $F^{2}$ by full-matrix leastsquares methods using the SHELX-2018 program package. All hydrogen atoms attached to carbon atoms were geometrically placed. Due to the highly porous and highly symmetric structure of $\mathbf{1}$, the lattice water molecules cannot be mapped by single-crystal X-ray diffractions. The residual electron density that could not sensibly be modeled as solvents were removed via application of the SQUEEZE function in PLATON. The final water guests in 1 were determined by the thermogravimetric analysis (Fig. S10). CCDC-2065522 contains the supplementary crystallographic data for compounds $\mathbf{1}$.

\section{Ionic conductivity experiments}

Alternating current impedance measurements were carried out with a SI 1260 IMPEDANCE/GAINPHASE analyzer operating at frequency ranging from $0.1 \mathrm{~Hz}$ to $10 \mathrm{MHz}$ with an applied voltage of $50 \mathrm{mV}$. The relative humidity was controlled by a STIK Corp CIHI150BS3 incubator. The sample was pressed to form a cylindrical pellet of crystalline powder sample $(\sim 1.0 \mathrm{~mm}$ thickness $\times 5 \mathrm{~mm} \phi)$ coated with C-pressed electrodes. Two silver electrodes were attached to both sides of pellet to form four end S3 terminals (quasi-four-probe method). The bulk conductivity was estimated by semicircle fittings of Nyquist plots. 


\section{Section S2 Additional tables}

Table S1 X-ray crystallographic data for $\mathbf{1}$

\begin{tabular}{|c|c|}
\hline & \\
\hline Empirical formula & $\mathrm{C}_{72} \mathrm{H}_{124} \mathrm{Cu}_{6} \mathrm{~K}_{2} \mathrm{LiN}_{12} \mathrm{Nb}_{8} \mathrm{O}_{78} \mathrm{Te}_{4}$ \\
\hline Formula weight & 4125.88 \\
\hline Crystal system & Orthorhombic \\
\hline Space group & Pnnn \\
\hline$a(\AA)$ & $12.7148(7)$ \\
\hline$b(\AA)$ & $16.4102(8)$ \\
\hline$c(\AA)$ & $33.8164(17)$ \\
\hline$\alpha\left(^{\circ}\right)$ & 90 \\
\hline$\beta\left(^{\circ}\right)$ & 90 \\
\hline$\gamma\left({ }^{\circ}\right)$ & 90 \\
\hline$V\left(\AA^{3}\right)$ & $7055.9(6)$ \\
\hline$Z$ & 2 \\
\hline$F(000)$ & 4030 \\
\hline$\rho_{\text {calcd }}\left(\mathrm{g} \mathrm{cm}^{-3}\right)$ & 1.942 \\
\hline Temperature $(\mathrm{K})$ & $175(2)$ \\
\hline Refl. Collected & 25704 \\
\hline Independent relf. & 6251 \\
\hline GOF on $\mathrm{F}^{2}$ & 0.998 \\
\hline Final $R$ indices $(I=2 \sigma(I))$ & $R_{1}=0.0573, w R_{2}==0.1409$ \\
\hline $\mathrm{R}$ indices (all data) & $R_{1}=0.0676, w R_{2}=0.1480$ \\
\hline
\end{tabular}


Table S2 The BVS calculations of all the $\mathrm{Nb}, \mathrm{Cu}$, Te and $\mathrm{Li}$ atoms.

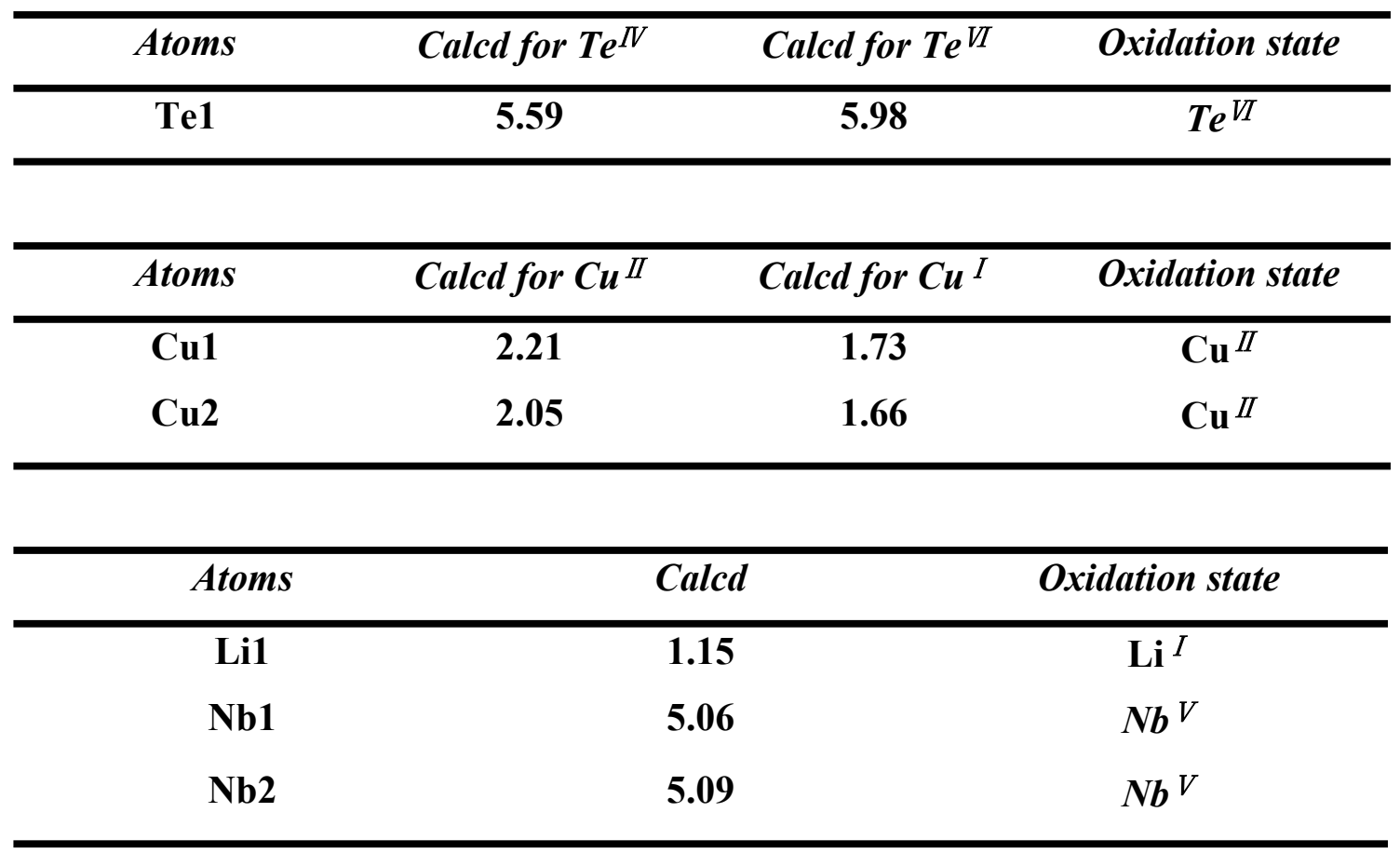

Table S3 Hydrogen Bond Lengths $(\AA)$ and Bond Angles $\left(^{\circ}\right)$ in 1.

\begin{tabular}{|c|c|c|c|c|c|}
\hline No. & D-H & $\mathbf{H} \cdots \mathbf{A}$ & D...A & $<$ (DHA) & Hydrogen bonds \\
\hline 1 & 0.93 & 2.30 & $2.783(5)$ & 111.9 & O1W-H1WA...O8 \\
\hline 2 & 0.93 & 2.23 & $3.130(6)$ & 161.9 & C12-H12A...O10_\$1 \\
\hline 3 & 0.93 & 2.60 & $3.095(6)$ & 114.0 & C13-H13A...O2 \\
\hline \multicolumn{6}{|c|}{ Symmetric codes: } \\
\hline \multicolumn{6}{|c|}{$\$ 1:-x+1 / 2,-y+1 / 2, z$} \\
\hline
\end{tabular}


Table S4 The intramolecular and intermolecular $\pi-\pi$ stacking parameters between phen ligands.

\begin{tabular}{|c|c|c|}
\hline Type & 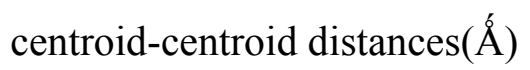 & dihedral angles $\left(^{\circ}\right)$ \\
\hline \multirow{5}{*}{$\begin{array}{l}\text { intramolecular } \pi-\pi \\
\text { stacking }\end{array}$} & 3.578 & \multirow{5}{*}{2.769} \\
\hline & 3.653 & \\
\hline & 3.677 & \\
\hline & 3.710 & \\
\hline & 3.955 & \\
\hline \multirow{5}{*}{$\begin{array}{l}\text { intermolecular } \pi-\pi \\
\text { stacking }\end{array}$} & 3.599 & \multirow{5}{*}{0.000} \\
\hline & 3.599 & \\
\hline & 3.604 & \\
\hline & 4.008 & \\
\hline & 4.008 & \\
\hline
\end{tabular}

Table S5 The calculation of the activation energy $\left(E_{\mathrm{a}}\right)$ of $\mathbf{1}$

\begin{tabular}{|c|c|c|c|c|c|c|}
\hline$T / \mathrm{K}$ & $1000 / T$ & $R / \Omega$ & $\sigma / \mathrm{S} \mathrm{cm}^{-1}$ & $\ln \sigma T$ & slope & $E_{\mathrm{a}}$ \\
\hline 298.15 & 3.35 & 71463 & $8.5 \times 10^{-6}$ & -5.98 & \multirow{3}{*}{-16.9} & \multirow{3}{*}{$E_{\mathrm{a}}=1.46 \mathrm{eV}$} \\
\hline 308.15 & 3.24 & 12491 & $4.9 \times 10^{-5}$ & -4.19 & & \\
\hline 318.15 & 3.14 & 2163.2 & $2.8 \times 10^{-4}$ & -2.42 & & \\
\hline 318.15 & 3.14 & 2163.2 & $2.8 \times 10^{-4}$ & -2.42 & \multirow{5}{*}{-4.82} & \multirow{5}{*}{$E_{\mathrm{a}}{ }^{\prime}=0.41 \mathrm{eV}$} \\
\hline 328.15 & 3.05 & 1226.9 & $4.9 \times 10^{-4}$ & -1.83 & & \\
\hline 338.15 & 2.96 & 932.3 & $6.6 \times 10^{-4}$ & -1.50 & & \\
\hline 348.15 & 2.87 & 696.1 & $8.8 \times 10^{-4}$ & -1.18 & & \\
\hline 358.15 & 2.79 & 402.8 & $1.5 \times 10^{-3}$ & -0.62 & & \\
\hline
\end{tabular}




\section{Section S3 Additional Structural Figures}

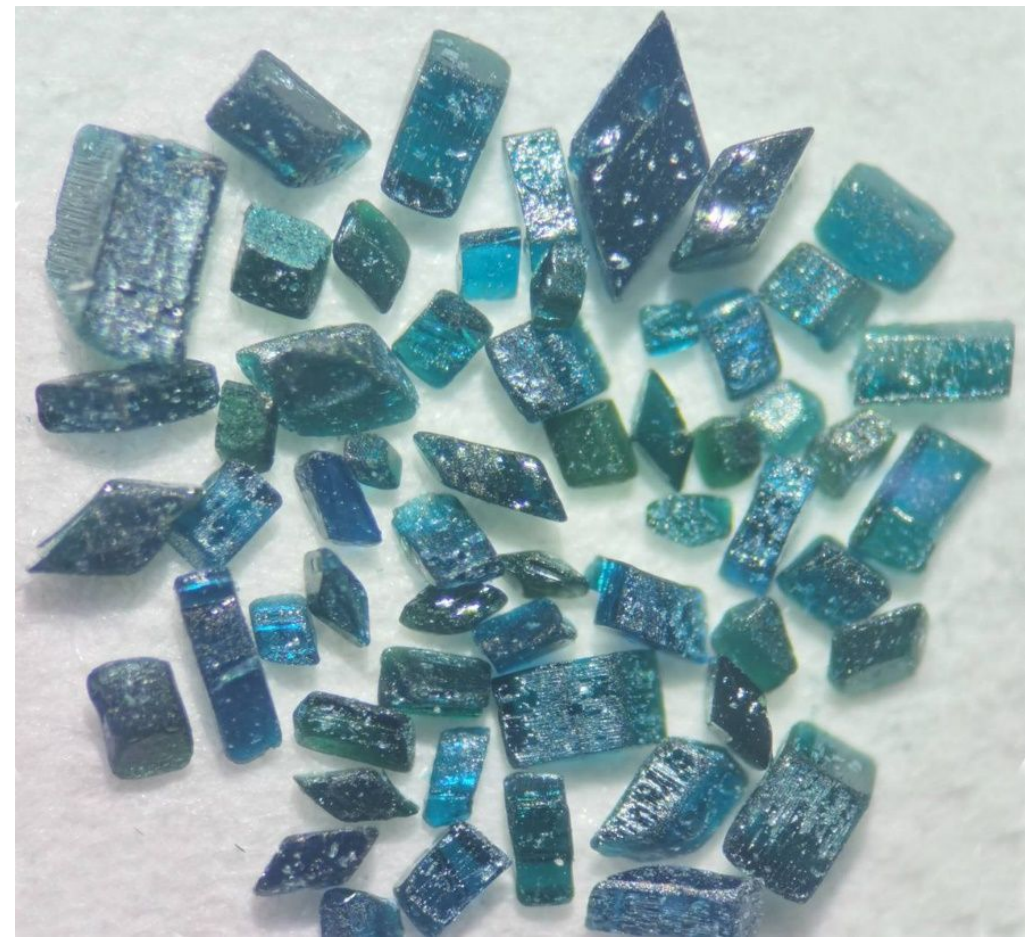

Fig. S1 The crystal morphology of compound 1 under an optical microscope.

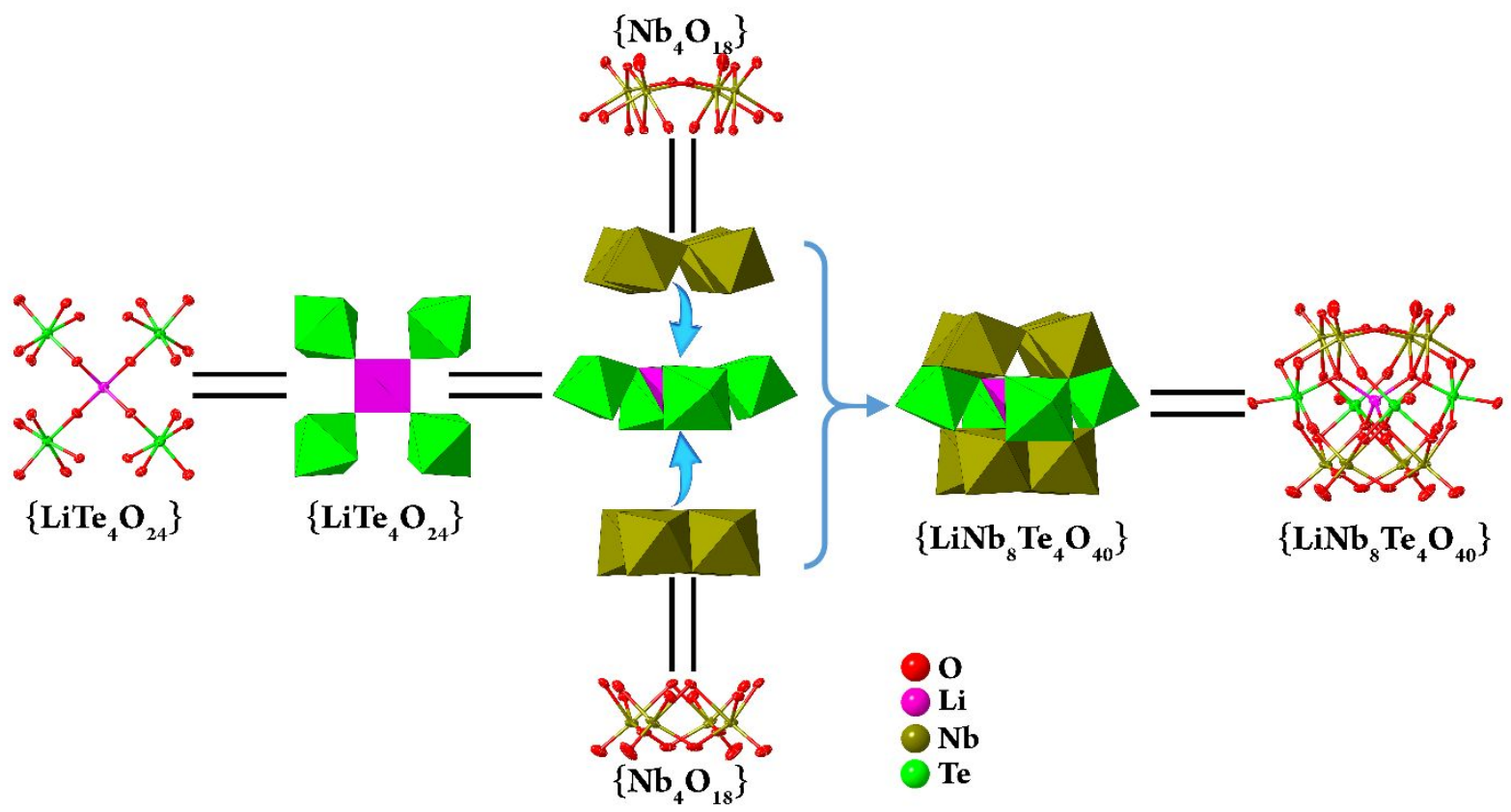

Fig. S2 The structural illustration of the Keggin-type $\left\{\mathrm{LiNb}_{8} \mathrm{Te}_{4} \mathrm{O}_{40}\right\}$ cluster. 


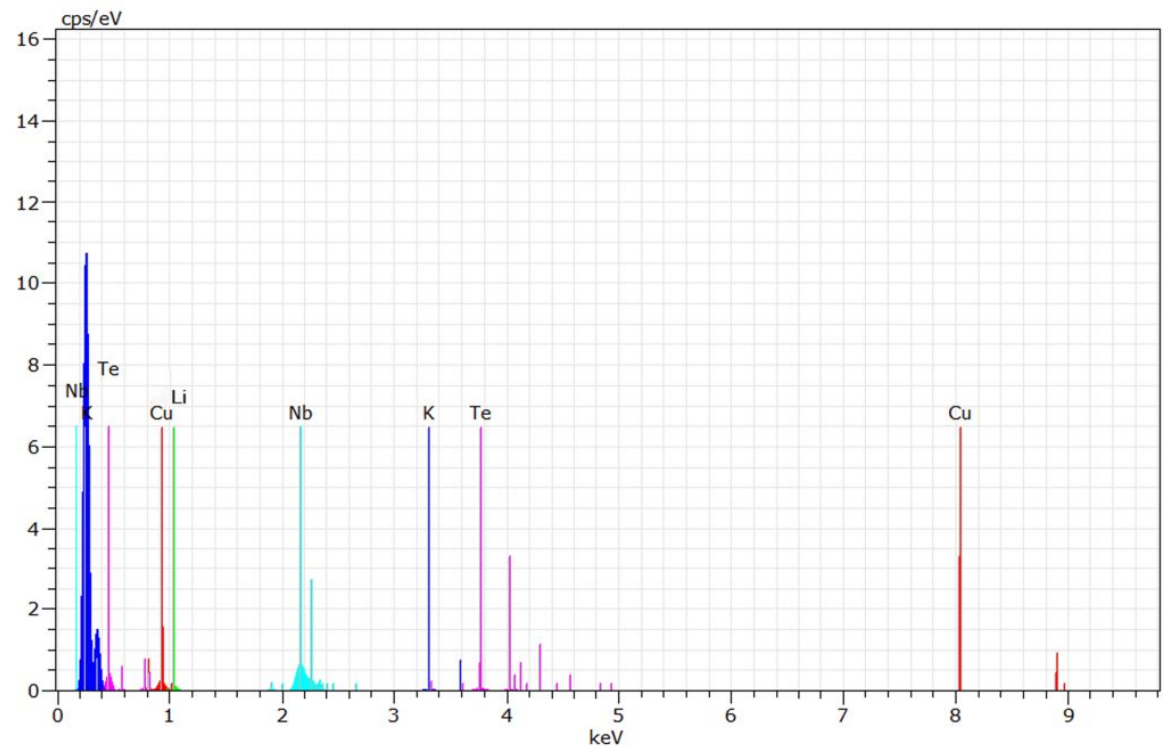

Fig. S3 Energy-dispersive X-ray spectroscopy of $\mathbf{1}$.

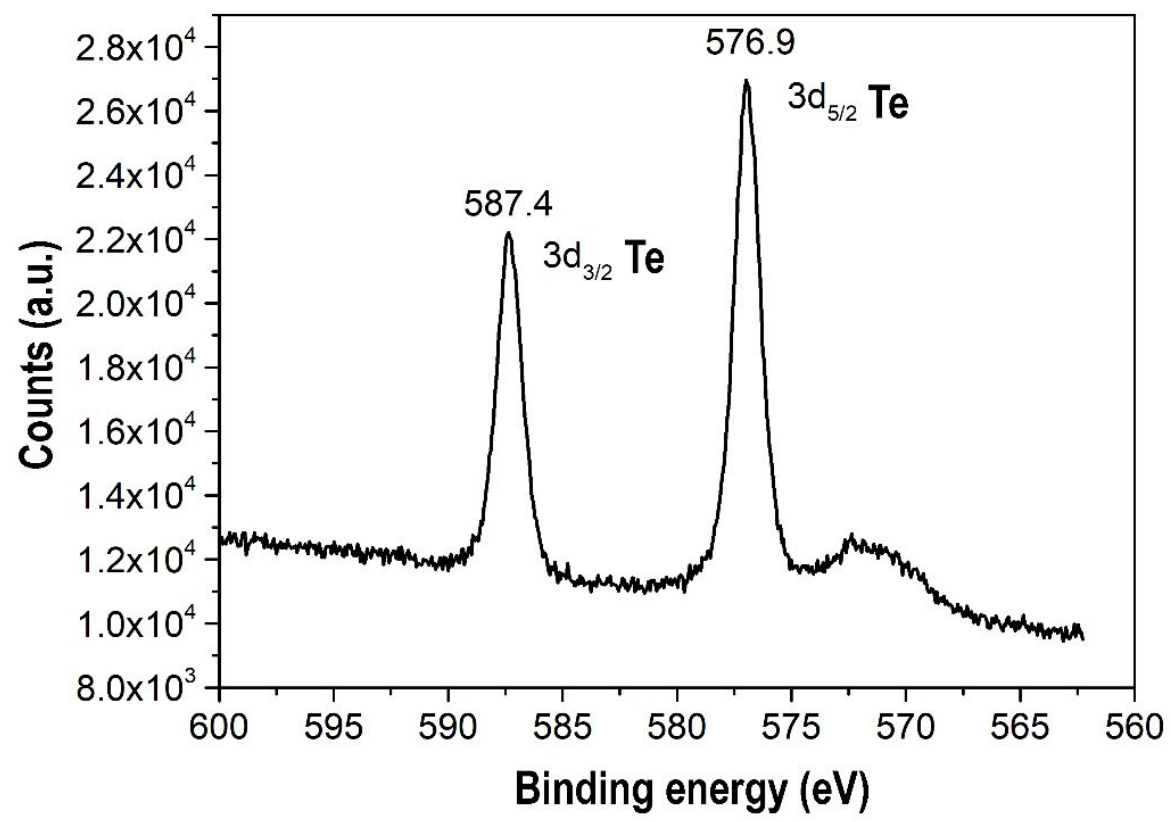

Fig. S4 XPS spectra of Te in $\mathbf{1 .}$ 

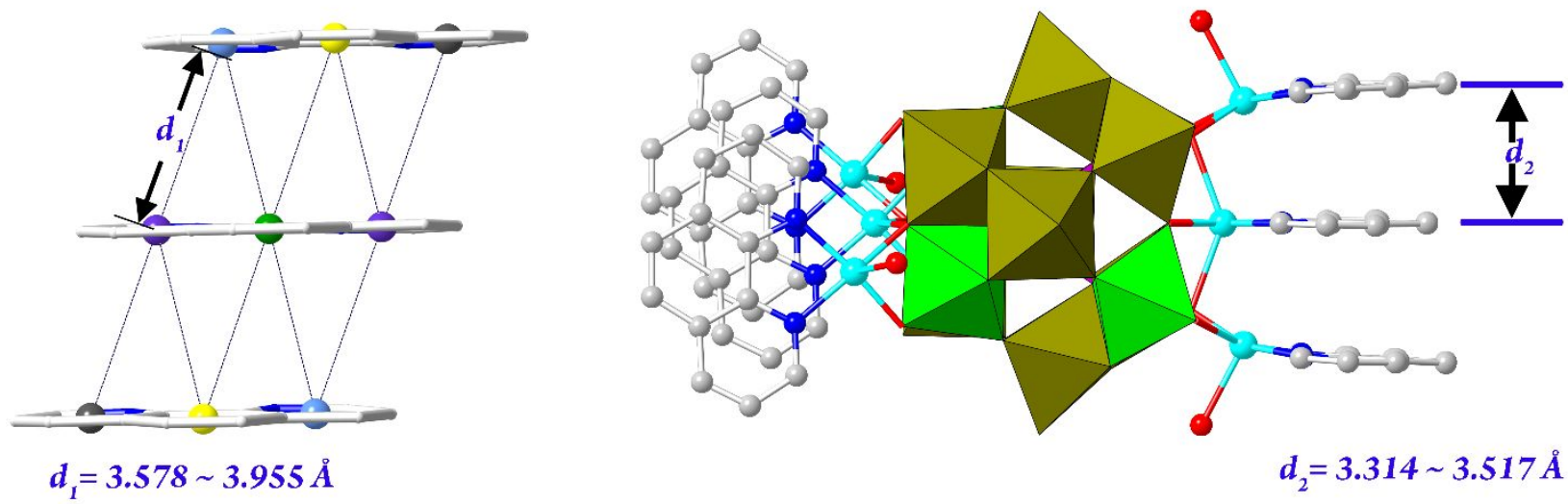

Fig. S5 The centroid distances between the aromatic rings and the perpendicular distances between the phen planes in the hybrid cluster.

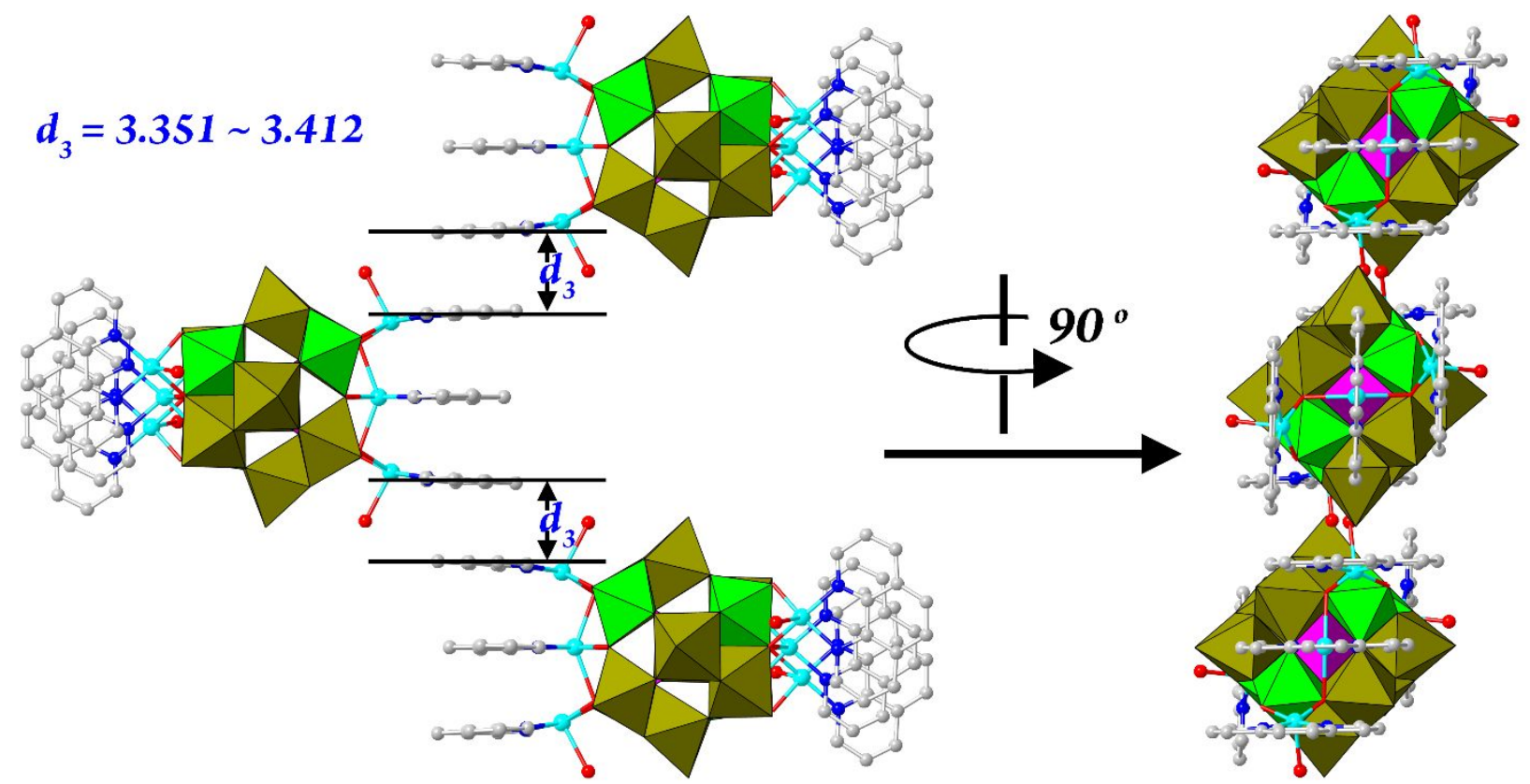

Fig. S6 The illustration of the $\pi-\pi$ interactions between neighboring two hybrid clusters. 


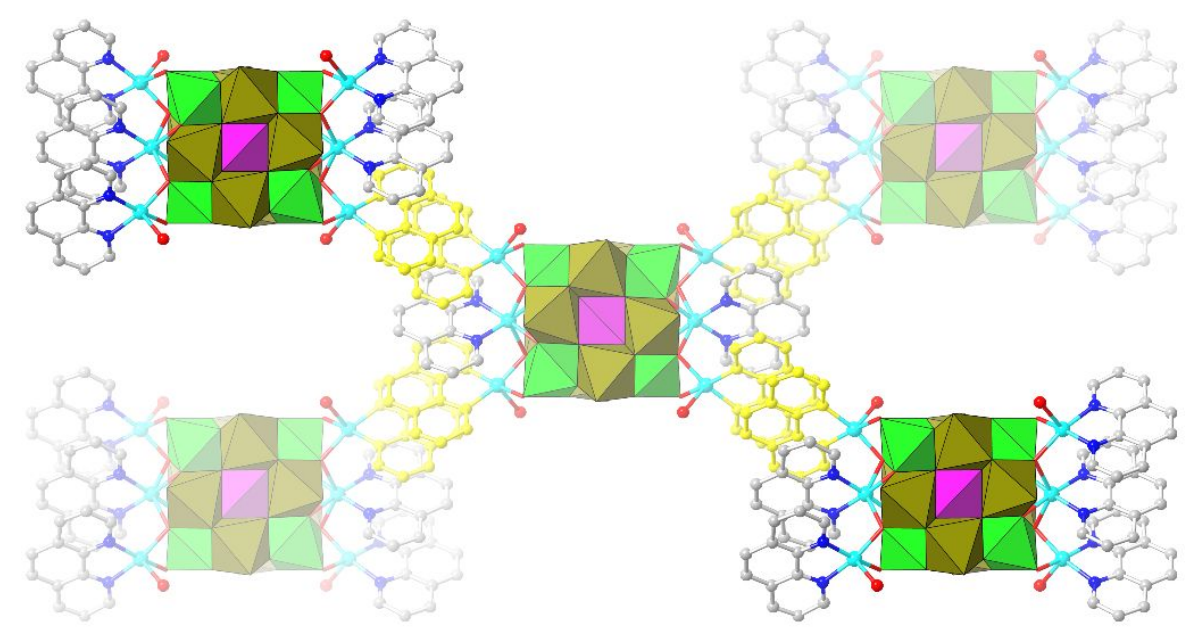

Fig. S7 The intermolecular $\pi-\pi$ interactions of each cluster with neighboring four clusters in two mutual perpendicular directions.

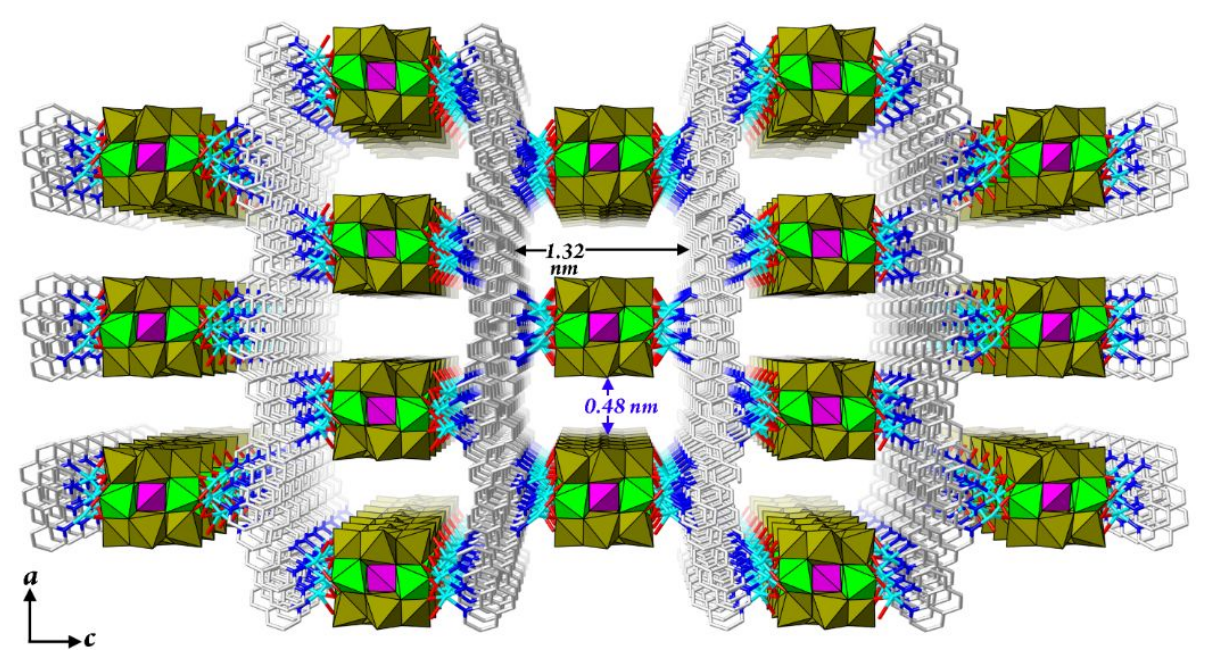

Fig. S8 The three-dimensional supramolecular framework structure based on the stacking of the hybrid cluster along $b$ axis. 


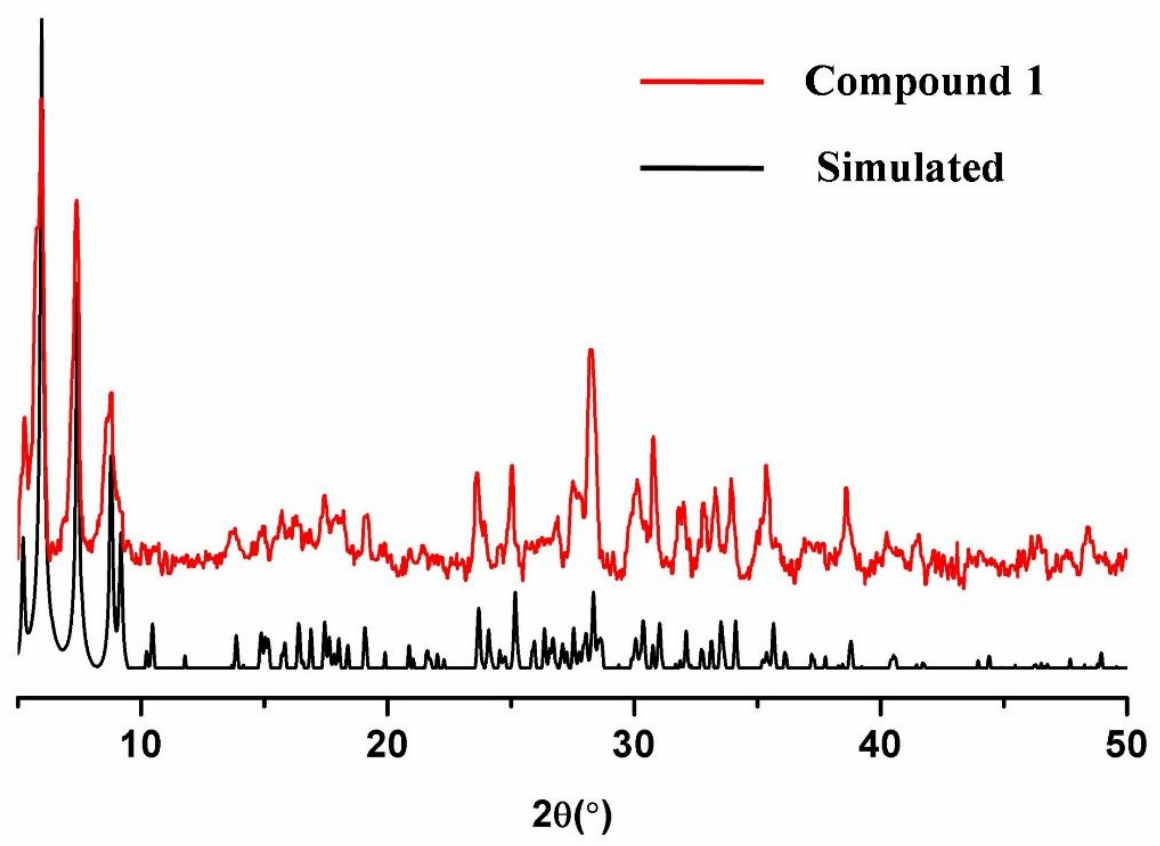

Fig. S9 Simulated and experimental PXRD patterns of 1.

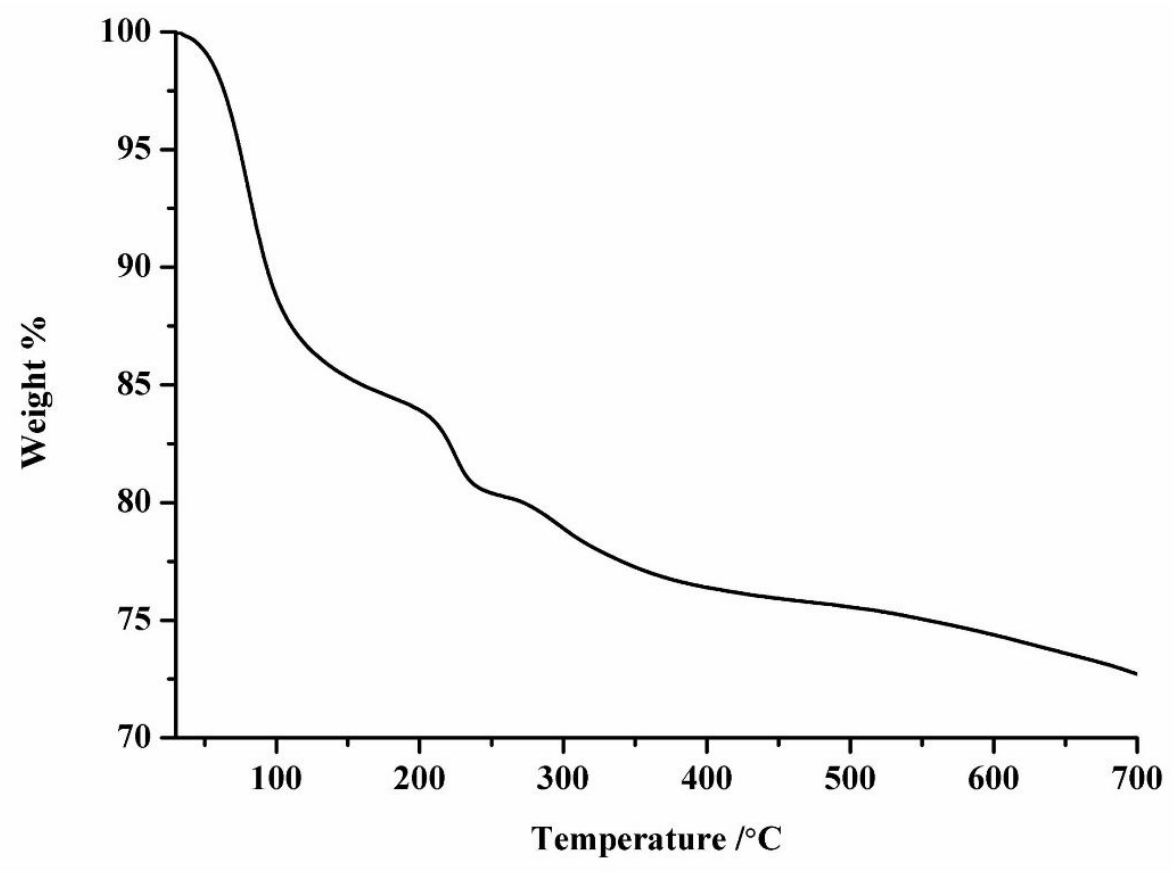

Fig. S10 TGA curve of 1 .

As shown in Fig. S10, 1 has a continuous weight loss process in the temperature range of 30 ${ }^{\circ} \mathrm{C}$ to $800{ }^{\circ} \mathrm{C}$. The first weight-loss of $15 \%$ in the temperature range of $30{ }^{\circ} \mathrm{C}$ to $200{ }^{\circ} \mathrm{C}$ can be ascribed to the removal of 34 lattice water molecules (calcd: 14.85\%). 


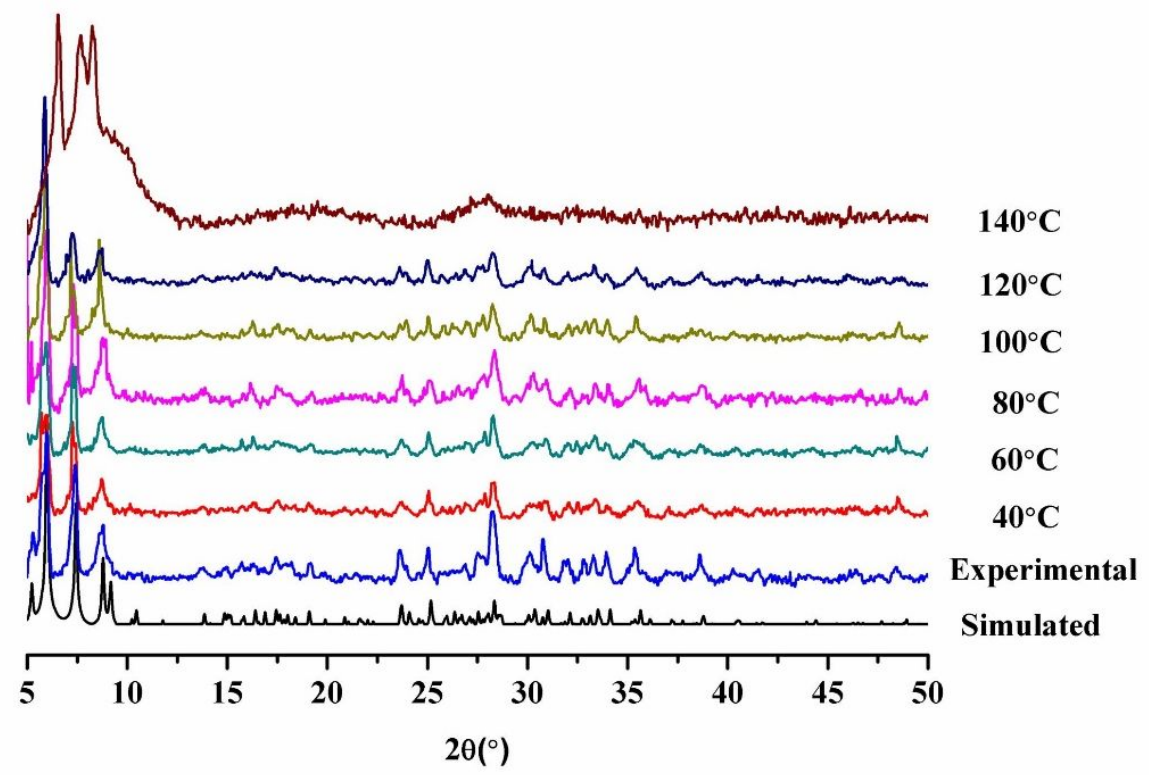

Fig. S11 Simulated and experimental variable-temperature PXRD patterns of 1.

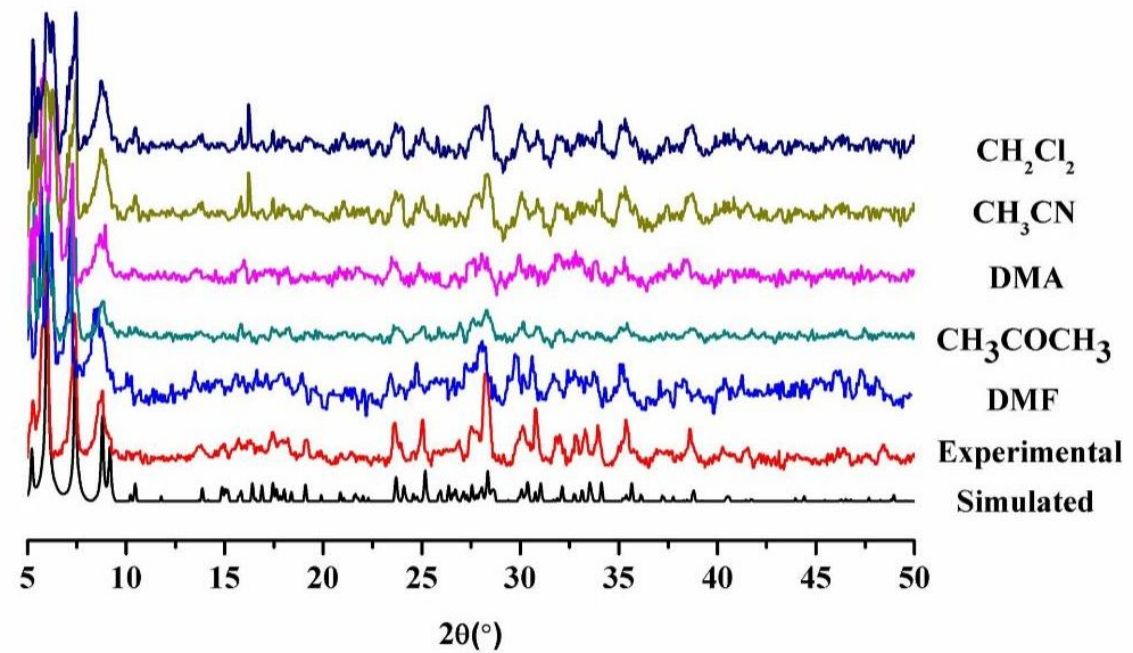

Fig. S12 Simulated PXRD pattern and experimental PXRD patterns of 1 soaked in different organic solvents for 24 hours. 


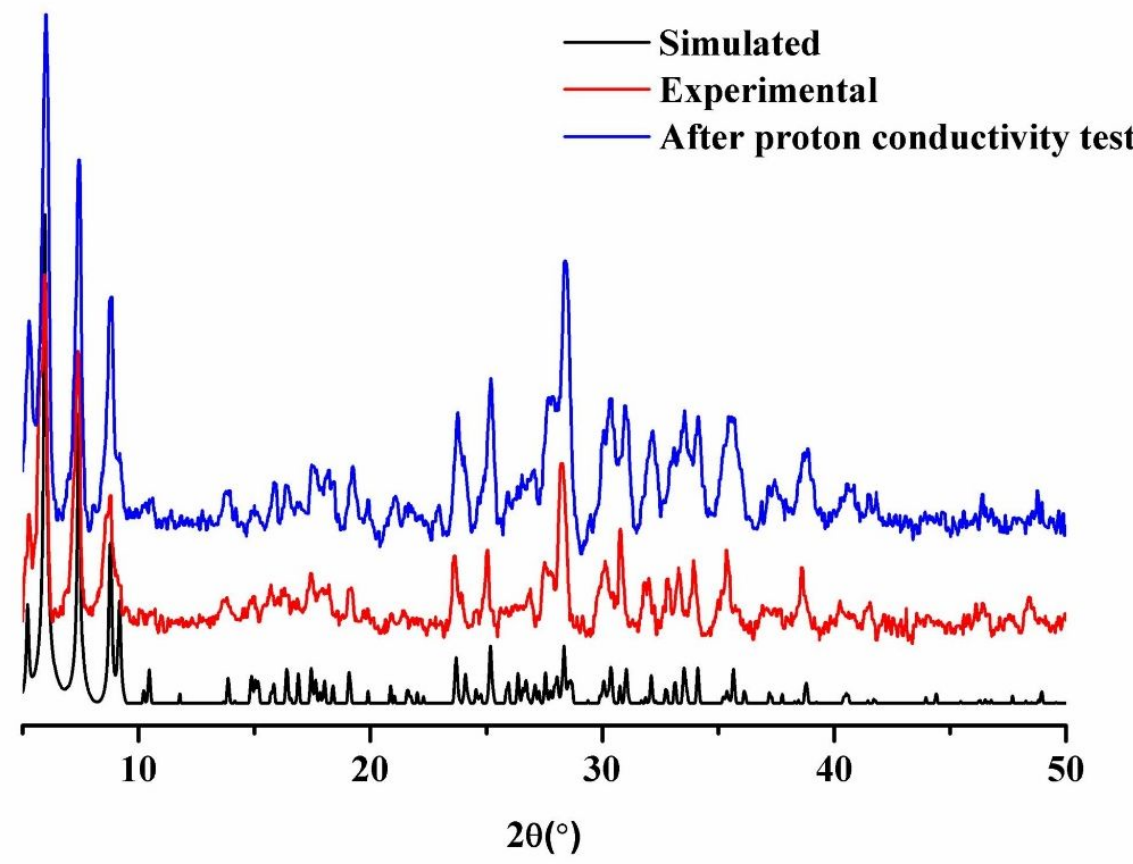

Fig. S13 Simulated PXRD pattern and experimental PXRD pattern of 1 after proton conduction test.

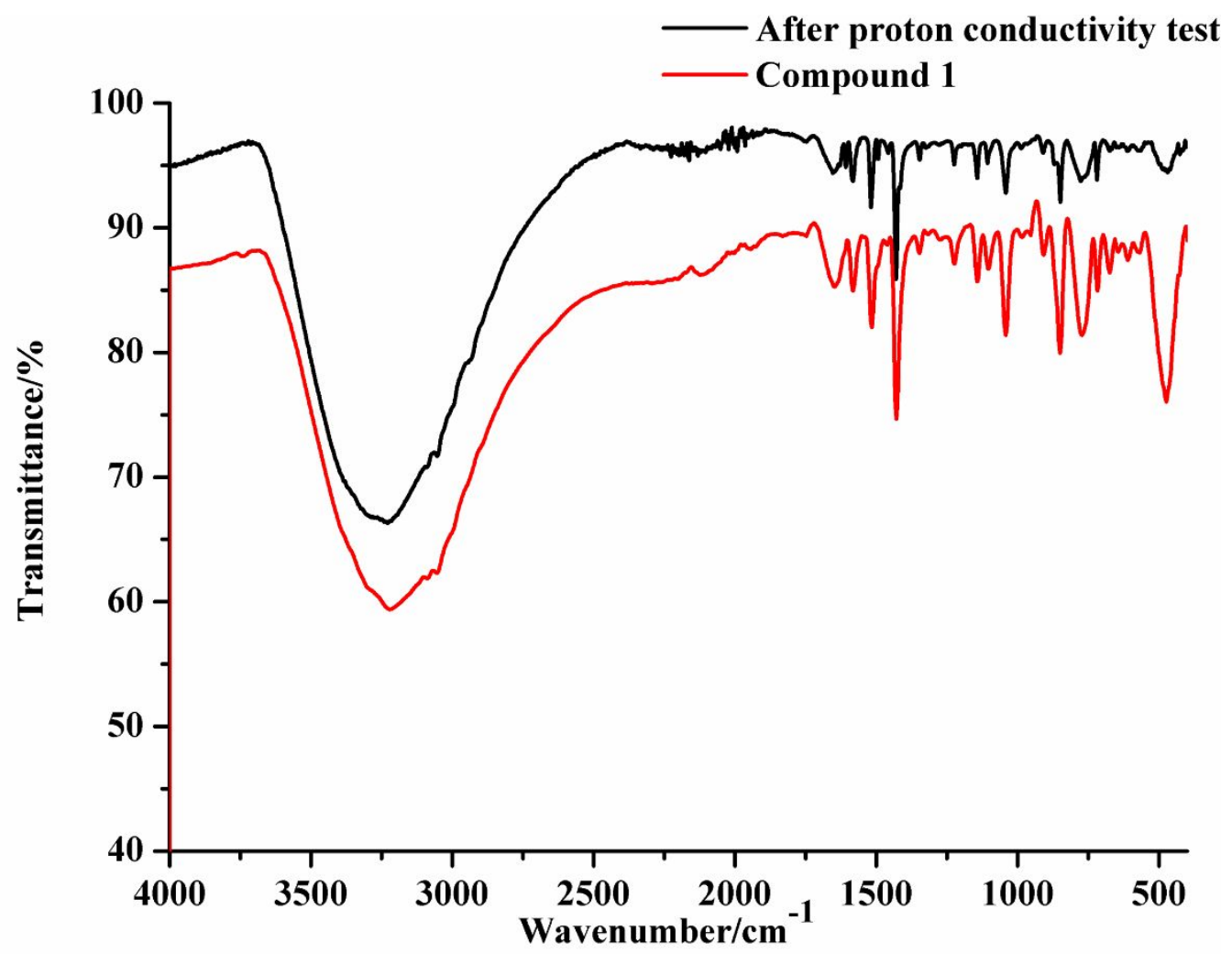


Fig. S14 Infrared spectra of the as-synthesized crystals and the sample after proton conduction test.

As shown in Fig. S14, the broad absorption peak at $3220 \mathrm{~cm}^{-1}$ is attributed to the $v(\mathrm{O}-\mathrm{H})$ stretching vibration of water. The $v(\mathrm{C}-\mathrm{H})$ and $v(\mathrm{~N}-\mathrm{H})$ stretching vibrations appear at about 2900 $\mathrm{cm}^{-1}$ and $3200 \mathrm{~cm}^{-1}$ and their bending vibrations adsorption appear at about $1427 \mathrm{~cm}^{-1}$ and 1521 $\mathrm{cm}^{-1}$. The absorption peak at about $1649 \mathrm{~cm}^{-1}$ and $1581 \mathrm{~cm}^{-1}$ is attributed to the aromatic ring vibration of phen. The absorption peak at about $1042 \mathrm{~cm}^{-1}$ is attributed to the stretching vibration peak of C-N. The peaks that appear in the range of 400 to $1000 \mathrm{~cm}^{-1}$ can be attributed to the characteristic absorption peak of $\mathrm{Nb}-\mathrm{O}$, of which $846 \mathrm{~cm}^{-1}$ is the stretching vibration peak of $v\left(\mathrm{Nb}-\mathrm{O}_{\mathrm{t}}\right), 774 \mathrm{~cm}^{-1}, 722 \mathrm{~cm}^{-1}, 626 \mathrm{~cm}^{-1}, 554 \mathrm{~cm}^{-1}$ and $473 \mathrm{~cm}^{-1}$ are the stretching vibration peaks of $v\left(\mathrm{Nb}-\mathrm{O}_{\mathrm{b}}-\mathrm{Nb}\right) .{ }^{\mathrm{S} 2}$ 


\section{Section 4: References}

[S1] C. M. Flynn and G. D. Stucky, Sodium 6-niobo(ethylenediamine)cobaltate(III) and its chromate(III) analog, Inorg. Chem., 1969, 8, 178.

[S2] Liang, Z.; Zhang, L.; Li, Y.; Ma, P.-T.; Niu, J.; Wang, J. Two Novel Heteropolyniobates Using $\mathrm{TeO}_{3}{ }^{2-}$ as Template and Linker. Inorg. Chem., 2019, 58, 27-30. 